\title{
The magnetic and structure properties of room-temperature ferromagnetic semiconductor $(\mathrm{Ga}, \mathrm{Mn}) \mathrm{N}$
}

\author{
Fuqiang Zhang ${ }^{\mathrm{a}, \mathrm{b}, *}$, NuoFu Chen ${ }^{\mathrm{a}, \mathrm{b}}$, Xianglin Liu ${ }^{\mathrm{a}}$, Zhikai Liu ${ }^{\mathrm{a}}$, Shaoyan Yang \\ Chunlin Chai ${ }^{\mathrm{a}}$

\footnotetext{
${ }^{a}$ Key Laboratory of Semiconductor Materials Science, Institute of Semiconductors, Chinese Academy of Sciences, P.O. Box 912, Beijing 100083, China

${ }^{\mathrm{b}}$ National Microgravity Laboratory of Chinese Academy of Sciences, Institute of Mechanics, Beijing 100080, China
}

Received 2 September 2003; accepted 7 October 2003

Communicated by R. Kern

\begin{abstract}
Diluted magnetic semiconductor $(\mathrm{Ga}, \mathrm{Mn}) \mathrm{N}$ were prepared by the implantation of $\mathrm{Mn}$ ions into $\mathrm{GaN}_{2} / \mathrm{Al}_{2} \mathrm{O}_{3}$ substrate. Clear X-ray diffraction peak from (Ga,Mn)N is observed. It indicates that the solid solution (Ga,Mn)N phase was formed with the same lattice structure as GaN and different lattice constant. Magnetic hysteresis-loops of the (Ga, Mn)N were obtained at room temperature $(293 \mathrm{~K})$ with the coercivity of about $2496.97 \mathrm{~A} \mathrm{~m}^{-1}$.
\end{abstract}

(C) 2003 Elsevier B.V. All rights reserved.

PACS: 75.50.Pp; 75.70.Ak; 81.05.Ea; 81.05.Zx; 81.15.Hi; 61.82.Fk

Keywords: A1. X-ray diffraction; A3. Ion beam deposition; B1. $\mathrm{GaN} / \mathrm{Al}_{2} \mathrm{O}_{3}$; B2. Ferromagnetic materials

\section{Introduction}

III-V based diluted magnetic semiconductors (DMSs) [1-5] have demonstrated unique phenomena such as field-effect control of ferromagnetism [6,7], efficient spin injection to produce circularly polarized light $[6,8,9]$, and spin-dependent resonant tunneling $[4,6]$. But the Curie temperature of DMSs is not high enough. According to a theoretical model considering ferromagnetic beha-

\footnotetext{
*Corresponding author. Key Laboratory of Semiconductor Materials Science, Institute of Semiconductors, Chinese Academy of Sciences, P.O. Box 912, Beijing 100083, China. Tel.: + 86-10-823-04627; fax: + 86-10-82304469.

E-mail address: fqzh@red.semi.ac.cn (F. Zhang).
}

vior of various DMSs $[10,11], \mathrm{GaMnN}$ with $\sim 5 \%$ $\mathrm{Mn}$ and high hole concentrations is predicted to have a Curie temperature above room temperature $[11,12]$. And GaN-based DMSs are quite promising for various spin-controlled and photonic devices because of the wide gap corresponding to visible light [13]. In order to obtain a heavy doping of $\mathrm{Mn}$ in $\mathrm{GaN}$, a highly nonequilibrium growth process is necessary [13]. One of the growth methods is the high-energy $\mathrm{Mn}$-ion implantation whose evident advantage is that the fabrication is easy. But the implanted highenergy $\mathrm{Mn}$ ions will seriously destroy the crystal structure which is impossible to restore by postannealing, and the formation of secondary phase is inevitable [14]. 
In this letter, two methods are adopted to overcome the disadvantages of high-energy ions implantation. One is the application of the lowenergy ions, which can weaken the damage to crystal structure, and the other is the application of the elevated substrate temperature [12], which helps to restore the crystal structure during the process of implantation and can make the $\mathrm{Mn}$ ions reach deeper in the layer of $\mathrm{GaN}$. $(\mathrm{Ga}, \mathrm{Mn}) \mathrm{N}$ samples were prepared by the implantation of lowenergy $\mathrm{Mn}$ ions into unintentionally doped n-type $\mathrm{GaN} / \mathrm{Al}_{2} \mathrm{O}_{3}$ substrate at different elevated substrate temperatures with mass-analyzed low-energy dual ion beam deposition system. Under optimized substrate temperature and annealing conditions, the solid solution $(\mathrm{Ga}, \mathrm{Mn}) \mathrm{N}$ phase in samples was found with the same lattice structure as $\mathrm{GaN}$ and different lattice constants.

The GaN epilayer was prepared by metal organic chemical vapor deposition (MOCVD) on sapphire substrates. (Ga,Mn)N samples were prepared by mass-analyzed low energy dual ion beam deposition system. There are magneto-mass filters in this system with which the manganese can be purified as pure as isotope. Firstly, the manganese ions with energy of $1 \mathrm{keV}$ were uniformly implanted into ( $\left.\begin{array}{llll}0 & 0 & 0 & 1\end{array}\right)$ oriented $\mathrm{GaN} /$ $\mathrm{Al}_{2} \mathrm{O}_{3}$ substrates in the depth of about $60 \mathrm{~nm}$. The dose of manganese ions was about $2.5 \times 10^{14} / \mathrm{cm}^{2}$. During implantation, $\mathrm{GaN} / \mathrm{Al}_{2} \mathrm{O}_{3}$ substrates were heated to $400^{\circ} \mathrm{C}$. Secondly, the manganese ions with energy of $100 \mathrm{eV}$ were deposited on the surface of the wafers with the dose of about $1.25 \times 10^{14} / \mathrm{cm}^{2}$ to prevent the implanted manganese ions from diffusing from the surface of the wafer during later annealing and to keep the content of $\mathrm{Mn}$ at a high level near the surface. Then, the samples were annealed at $800^{\circ} \mathrm{C}$ for $30 \mathrm{~s}$ under flowing $\mathrm{N}_{2}$ gas.

X-ray diffraction (XRD) was applied for structure analyses. The wavelength of $\mathrm{X}$-ray radiated from the $\mathrm{Cu} \mathrm{K} \alpha$ is $0.1540562 \mathrm{~nm}$. XRD patterns of the samples were measured with $2 \theta-\theta$ scan. Other reflections were not found in these X-ray diffraction measurements except the reflections from $\mathrm{GaN}$ and $\mathrm{Al}_{2} \mathrm{O}_{3}$. Fig. 1 is the fine structure of the XRD pattern around $\left(\begin{array}{llll}0 & 0 & 0 & 2\end{array}\right)$ reflection from a sample (solid line). The diffraction curve of GaN/

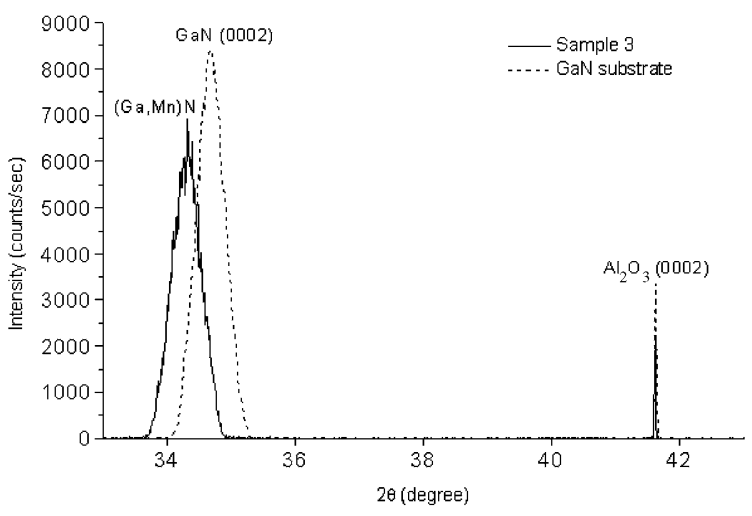

Fig. 1. X-ray diffraction curves of a $(\mathrm{Ga}, \mathrm{Mn}) \mathrm{N}$ sample (solid line) and a $\mathrm{GaN} / \mathrm{Al}_{2} \mathrm{O}_{3}$ substrate (dashed line).

$\mathrm{Al}_{2} \mathrm{O}_{3}$ substrate is the dashed line. There is no change in the diffraction curve of $\mathrm{Al}_{2} \mathrm{O}_{3}$, because the implanted $\mathrm{Mn}$ ions do not affect the structure of $\mathrm{Al}_{2} \mathrm{O}_{3}$. Compared with the dashed line in Fig. 1, clear diffraction peak from $(\mathrm{Ga}, \mathrm{Mn}) \mathrm{N}$ is observed and the peak difference between $(\mathrm{Ga}, \mathrm{Mn}) \mathrm{N}$ and $\mathrm{GaN}$ is $0.357^{\circ}$. It indicates that implanted $\mathrm{Mn}$ atoms are incorporated in the wurtzite structure as substitutional atoms of $\mathrm{Ga}$ or interstitial atoms in $\mathrm{GaN}$. The solid solution $(\mathrm{Ga}, \mathrm{Mn}) \mathrm{N}$ structure is formed in $\mathrm{GaN} / \mathrm{Al}_{2} \mathrm{O}_{3}$ substrates. The even lattice expand ratio of the $(\mathrm{Ga}, \mathrm{Mn}) \mathrm{N}$ layer is calculated as $1.008 \%$ from the peak position of $(\mathrm{Ga}, \mathrm{Mn}) \mathrm{N}$ diffraction patter according to Fig. 1.

The magnetic properties of the $(\mathrm{Ga}, \mathrm{Mn}) \mathrm{N}$ samples were studied using superconducting quantum interference device (SQUID) magnetometer MPMS7. The measurements were carried out at room temperature ( 293 K). Fig. 2 shows the typical hysteresis-loop measured by SQUID from a $(\mathrm{Ga}, \mathrm{Mn}) \mathrm{N}$ sample. The highest saturation magnetization and residual magnetization, respectively, are $2.1141 \times 10^{-4}$ and $2.4002 \times 10^{-5}$ e.m.u. The largest coercive force in these samples is $2496.97 \mathrm{~A} \mathrm{~m}^{-1}$. These results confirm that these $(\mathrm{Ga}, \mathrm{Mn}) \mathrm{N}$ samples are ferromagnetic at room temperature. The magnetization decreases after the magnetic field surpasses the saturation value in Fig. 2. The reason is that the GaN substrate is diamagnetic, and with the increase of magnetic field, the diamagnetic field in $\mathrm{GaN}$ becomes obvious. 


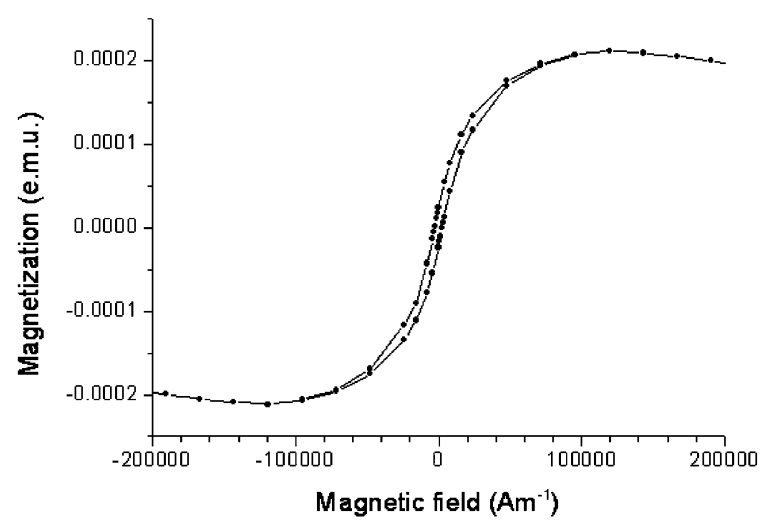

Fig. 2. Magnetic hysteresis-loop measured by SQUID magnetometer from a $(\mathrm{Ga}, \mathrm{Mn}) \mathrm{N}$ sample.

In summary, room-temperature ferromagnetic semiconductor $(\mathrm{Ga}, \mathrm{Mn}) \mathrm{N}$ were prepared with mass-analyzed low energy dual ion beam deposition system. Clear X-ray diffraction peaks from $(\mathrm{Ga}, \mathrm{Mn}) \mathrm{N}$ samples are observed. It indicates that the solid solution $(\mathrm{Ga}, \mathrm{Mn}) \mathrm{N}$ structure is formed with the same lattice structure of $\mathrm{GaN}$ and the bigger lattice constant. No evident secondary phase is found in our samples. Magnetic hysteresis-loops were obtained from the (Ga,Mn)N samples with SQUID magnetometer at $293 \mathrm{~K}$.

This work is partly sponsored by National Natural Science Foundation of China under contract 60176001, the Ministry of Chinese
National Science and Technology under contract PAN95-YU-34, Special Funds for Major State Basic Research Projects G20000683, G20000365 and G2002CB311905.

\section{References}

[1] T. Hayashi, M. Tanaka, T. Nishinaga, H. Shimada, J. Appl. Phys. 81 (1997) 4865.

[2] H. Ohno, H. Munekata, S. Molnar, L.L. Chang, J. Appl. Phys. 69 (1991) 6103.

[3] N. Karar, S. Basu, R. Venkatarghavan, B.M. Aror, J. Appl. Phys. 88 (2000) 924.

[4] H. Ohno, Science 281 (1998) 951.

[5] H. Ohno, Appl. Phys. Lett. 69 (1996) 363.

[6] N. Theodoropoulou, A.F. Hebard, Phys. Rev. Lett. 89 (2002) 107203.

[7] H. Ohno, D. Chiba, F. Matsukura, T. Omiya, E. Abe, T. Dietl, Y. Ohno, K. Ohtani, Nature 408 (2000) 944.

[8] R. Fiederling, M. Keim, G. Reuscher, W. Ossau, G. Schmidt, A. Waag, L.W. Molenkamp, Nature 402 (1999) 787.

[9] Y. Ohno, D.K. Young, B. Beschoten, F. Matsukura, H. Ohno, D.D. Awschalom, Nature 402 (1999) 790.

[10] J. Konig, H.H. Lin, A.H. MacDonald, Phys. Rev. Lett. 84 (2000) 5628.

[11] T. Diehl, H. Ohno, F. Matsukura, J. Cibert, D. Ferrand, Science 287 (2000) 1019.

[12] N. Theodoropoulou, A.F. hebard, Appl. Phys. Lett. 78 (22) (2001) 3475.

[13] E. Kulatov, H. Nakayama, Phys. Rev. B 66 (2002) 045203.

[14] Yoon Shon, Young Hae Kwon, Deuk Young Kim, Xiangjun Fan, Dejun Fu, Tae Won Kang, Jpn. J. Appl. Phys. 40 (2001) 5304. 